\section{Intravenous iron preparations transiently generate non-transferrin-bound iron from two proposed pathways}

\author{
Maciej W. Garbowski, ${ }^{1-3}$ Sukhvinder Bansal, ${ }^{2}$ John B. Porter, ${ }^{1}$ Claudio Mori, ${ }^{4}$ \\ Susanna Burckhardt ${ }^{4}$ and Robert C. Hider ${ }^{2,3}$ \\ ${ }^{1}$ University College London (UCL) Cancer Institute, Hematology Department, London, \\ UK; ' ${ }^{K}$ King's College London (KCL), Institute of Pharmaceutical Science, London, UK; \\ ${ }^{3}$ London Metallomics Consortium, London, UK and ${ }^{4}$ Vifor Pharma Group, Glattbrugg, \\ Switzerland
}

\section{ABSTRACT}

I ntravenous iron-carbohydrate complex preparations (IVIP) are noninterchangeable pro-drugs: their pharmacokinetics $(\mathrm{PK})$ varies determined by semi-crystalline iron core and carbohydrate shell structures, influences pharmacodynamics (PD) and thus efficacy and safety. Examining PK/PD relationships of three IVIP we identify a two-pathway model of transient non-transferrin-bound iron (NTBI) generation following single dose administration. Twenty-eight hypoferremic non-anemic patients randomized to $200 \mathrm{mg}$ iron as ferric carboxymaltose (Fe-carboxymaltose), iron sucrose (Fe-sucrose), iron isomaltoside 1000 (Fe-isomaltoside-1000), $\mathrm{n}=8 / \mathrm{arm}$, or placebo, $\mathrm{n}=4$, on a 2 -week $\mathrm{PK} / \mathrm{PD}$ study, had samples analysed for total serum iron, IVIP-iron, transferrin-bound iron (TBI) by high-performance liquid chromatography in combination with inductively coupled plasma mass spectrometry (HPLC-ICP-MS), transferrin saturation (TSAT), serum ferritin (s-Ferritin) by standard methods, NTBI and hepcidin as published before. IVIP-dependent increases in these parameters returned to baseline in 48-150 hours (h), except for s-Ferritin and TSAT. NTBI was low with Fe-isomaltoside-1000 $(0.13 \mu \mathrm{M}$ at $8 \mathrm{~h})$, rapidly increased with Fe-sucrose $(0.8 \mu \mathrm{M}$ at $2 \mathrm{~h}$, $1.25 \mu \mathrm{M}$ at $4 \mathrm{~h})$, and delayed for Fe-carboxymaltose $(0.57 \mu \mathrm{M}$ at $24 \mathrm{~h})$. NTBI area-under-curve (AUC) were 7-fold greater for Fe-carboxymaltose and Fe-sucrose than for Fe-isomaltoside-1000. Hepcidin peak time varied, but not AUC or mean levels. s-Ferritin levels and AUC were highest for Fe-carboxymaltose and greater than placebo for all IVIP. We propose two mechanisms for the observed NTBI kinetics: rapid and delayed NTBI appearance consistent with direct (circulating IVIP-to-plasma) and indirect (IVIP-to-macrophage-to-plasma) iron release based on IVIP plasma half-life and s-Ferritin dynamics. IVIP generate different, broadly stability- and PK-dependent, NTBI and s-Ferritin signatures, which may influence iron bioavailability, efficacy and safety. Longer-term studies should link NTBI exposure to subsequent safety and efficacy parameters and potential clinical consequences.

\section{Introduction}

Non-transferrin-bound iron (NTBI) collectively refers to a heterogeneous group of plasma iron species that are not bound to transferrin, ferritin or heme typically present with transferrin saturation (TSAT) $>75 \% .{ }^{1,2}$ In iron overload conditions these are thought to comprise ferric citrate species, mostly albumin-bound, some of which are more redox-active than others. ${ }^{3}$ NTBI species, present in iron-overloaded patients, are responsible for the pattern of atypical tissue iron distribution seen under such conditions, including extrahepatic (endocrine and myocardial) hemosiderosis. ${ }^{4}$ However, the intravenous iron-carbohydrate complex preparations (IVIP) themselves are not considered to represent NTBI, or the redox-active, weakly-bound species, although they can become the source of both. Following IVIP infusion, in principle, NTBI could be generated by either a rapid iron egress from
Ferrata Storti Foundation

Haematologica 2021

Volume 106(11):2885-2896

Correspondence:

MACIEJ GARBOWSKI

maciej.garbowski@ucl.ac.uk

Received: February 20, 2020.

Accepted: September 3, 2020.

Pre-published: September 14, 2020.

https://doi.org/10.3324/haematol.2020.250803

(C)2021 Ferrata Storti Foundation

Material published in Haematologica is covered by copyright. All rights are reserved to the Ferrata Storti Foundation. Use of published material is allowed under the following terms and conditions:

https://creativecommons.org/licenses/by-nc/4.0/legalcode. Copies of published material are allowed for personal or internal use. Sharing published material for non-commercial purposes is subject to the following conditions:

https://creativecommons.org/licenses/by-nc/4.0/legalcode, sect. 3. Reproducing and sharing published material for commercial purposes is not allowed without permission in writing from the publisher. 
macrophages following primary uptake into the macrophage system or by intravascular iron release from the circulating IVIP prior to macrophage uptake. The structure of the IVIP being administered is likely to influence the levels and duration of both NTBI components. These are largely un-described however, and are compared here for three different IVIP.

IVIP have become increasingly used in the treatment of iron deficiency within the context of a wide range of diseases. $^{5}$ All of these preparations are pro-drugs ${ }^{6,7}$ for bioavailable iron but their exact mode of iron delivery is unclear. ${ }^{5}$ This remains poorly recognized despite their widespread use. ${ }^{5}$ It has been suggested that, depending on the nature of the carbohydrate shell, some IVIP partly decompose in plasma before macrophage uptake; their subsequent endolysosomal degradation releases iron for transient storage or export to plasma. ${ }^{8}$

Available IVIP include iron sucrose (Fe-sucrose), ferric carboxymaltose (Fe-carboxymaltose), sodium ferric gluconate, iron isomaltoside 1000 (Fe-isomaltoside-1000), ferumoxytol, and low molecular weight iron dextran. Depending on the carbohydrate shell type, these preparations can be classified as non-dextran-based and dextran/dextran-based complexes. ${ }^{9}$ Non-dextran-based complexes exhibit a correlation between molecular weight (MW) distribution and complex stability, i.e., higher MW complexes are more stable and have lower labile iron content than lower MW complexes. In contrast, dextran/dextran-based complexes are all very stable independent of their MW. . $^{510}$

Here, we selected two non-dextran-based IVIP with different MW distributions, Fe-carboxymaltose (Ferinject ${ }^{\circledR}$, $145-155 \mathrm{kDa}$ ) and Fe-sucrose (Venofer ${ }^{\circledR}, 42-44 \mathrm{kDa}$ ), as well as a dextran-based complex Fe-isomaltoside-1000 (Monofer $\left.^{\circledR}, 63-69 \mathrm{kDa}\right) .^{5}$ The purpose of this study was to examine the NTBI profiles in the context of other pharmacokinetics/pharmacodynamics (PK/PD) parameters under identical conditions $(200 \mathrm{mg}$ iron dose administered over 10 minutes [min]), in hypoferremic, otherwise healthy, subjects, to better understand their mode of action. Previous studies showed that all three preparations are known to transiently increase TSAT with decay half-lives $\mathrm{t}_{1 / 2}=23$ hours $(\mathrm{h})$ (Fe-isomaltoside-1000), $\mathrm{t}_{1 / 2}=8 \mathrm{~h}$ (Fe-carboxymaltose), and $t_{1 / 2}=5 \mathrm{~h}$ (Fe-sucrose), ${ }^{11}$ possibly with associated NTBI. ${ }^{12,13}$ Crucially however, appropriate NTBI and TSAT methods are necessary that distinguish between IVIP-Fe, TBI and NTBI. We used a highly sensitive and specific bead-based NTBI assay that is robust to transferrin. ${ }^{1,14}$ This means that due to the hexadentate nature of the assay chelator on the beads (CP851) iron is neither removed from ferrotransferrin nor donated (shuttled) to apotransferrin, thus minimizing nonspecific overestimation or underestimation of NTBI, respectively. ${ }^{1,14}$

Different IVIP display different iron pharmacokinetics, dependent on the structure of the semi-crystalline iron core and the type of polysaccharide ligand. ${ }^{7,15}$ Such properties may influence IVIP efficacy and safety, ${ }^{11,16}$ but also inform the mechanisms of iron delivery and IVIP differences. PK, stability, and the amount of weakly-bound iron, define the maximal single dose that can be administered. This is relevant, as the increased IVIP use is also linked to the fact that, with new preparations, high doses can be given in a short amount of time.

Therefore, following a single dose of $200 \mathrm{mg}$ iron, we monitored, among others, the PK of the IVIP, TSI (TBI,
NTBI and IVIP-Fe), TSAT, hepcidin and s-Ferritin levels over a period of 2 weeks. Although there have been some direct comparisons between different IVIP, ${ }^{17-19}$ none have compared the above six parameters in man, over a 2 -week period. This approach has allowed us to identify two proposed pathways of NTBI generation in IVIP treatment.

\section{Methods}

\section{Study design and patient population}

Our work is part of an exploratory phase I single-center, singleblind, randomized, placebo-controlled study to describe and characterize the PK and PD of Fe-carboxymaltose, Fe-sucrose, and Feisomaltoside-1000 in hypoferremic non-anemic subjects. Twentyeight subjects (hemoglobin $[\mathrm{Hb}] \geq 13 \mathrm{~g} / \mathrm{dL}$ for males, and $\geq 12 \mathrm{~g} / \mathrm{dL}$ for females, fasting s-Ferritin $<30 \mu \mathrm{g} / \mathrm{L}$ and TSAT $<20 \%$ measured at 08:00-09:00 a.m.) randomized into one of three treatment groups ( $n=8 / \mathrm{arm})$, or one placebo control group ( $\mathrm{n}=4 / \mathrm{arm}$ ), received a single intravenous $200 \mathrm{mg}$ iron dose of Fe-carboxymaltose, Fe-sucrose or Fe-isomaltoside-1000, or saline solution (placebo) over 10 minutes. Blood samples, processed for serum and batch-frozen at $-80^{\circ} \mathrm{C}$, were taken on day -1 at 08:00-09:00, then 4 and $12 \mathrm{~h}$ later (baseline iron profile); on day 1 immediately predose at 08:00-09:00 (time: $0 \mathrm{~min}$ ), $10 \mathrm{~min}$ (immediately post-dose), $20 \mathrm{~min}$, and $40 \mathrm{~min}$, then $1,2,4,6,8,12,16,24 \mathrm{~h}$, then $36,48,72$, $96,120,144$, and $312-336 \mathrm{~h}$ post-dose. The study was approved by a local Ethics Committee and all patients gave informed consent on entering the study.

\section{Serum iron profiles and s-Ferritin levels}

Vifor Pharma performed all assays except as stated. TSI was measured using a validated inductively coupled plasma optical emission spectroscopy method. Unsaturated iron binding capacity (UIBC) was measured by a photometric colorimetric test (Beckman Coulter UIBC Metabolite assay). TBI was calculated as $T B I[\mu \mathrm{mol} / \mathrm{L}]=($ transferrin $[\mathrm{g} / \mathrm{l}] \times 25.12)-U I B C[\boldsymbol{\mu} \mathrm{mol} / \mathrm{L}]$ where transferrin concentration was measured immuno-turbidimetrically (Beckman Coulter Transferin assay). Conversion of TBI units: $T B I[\mu \mathrm{g} / \mathrm{mL}]=T B I[\mu \mathrm{mol} / \mathrm{L}] \times 55.845[\mu \mathrm{g} / \mu \mathrm{moL}] \times 0.001[\mathrm{~L} / \mathrm{mL}]$. TSAT was

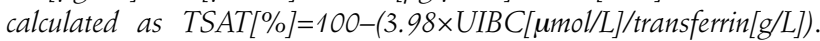
UIBC values below the lower limit of quantification were imputed as 0 in the TBI formula. S-Ferritin was measured with a chemiluminescent microparticle immunoassay (Architect systems), hemoglobin and reticulocytes using standard methods, and soluble transferrin receptor-1 (sTfR1) by particle-enhanced immunonephelometry (N Latex sTfR assay). IVIP-Fe was determined subtracting TBI from TSI. ${ }^{20}$

\section{Non-transferrin-bound iron}

We used the previously published bead-NTBI method ${ }^{1,14}$ with some modifications (see the Online Supplementary Appendix). Serum samples or buffered solutions incubated with the CP851 beads were assayed by flow-cytometry (Beckman Coulter CytoFLEX, CytExpert software, KCL) and quantitated against ferric nitrilotriacetate (Fe-NTA) standards (Figure 1). Limit of blank was $0.51 \mathrm{nM}$, limit of detection $14.6 \mathrm{nM}$, limit of quantitation 30 $\mathrm{nM}$; intra-assay and inter-assay precision coefficient of variation (CV) were $1.28 \%$ and $4.34 \%$, respectively (for further details see the Online Supplementary Appendix).

\section{Plasma hepcidin}

Plasma hepcidin (KCL) was measured in serum samples using tandem mass spectrometry; ${ }^{21}$ for detailed method see the Online Supplementary Appendix. 


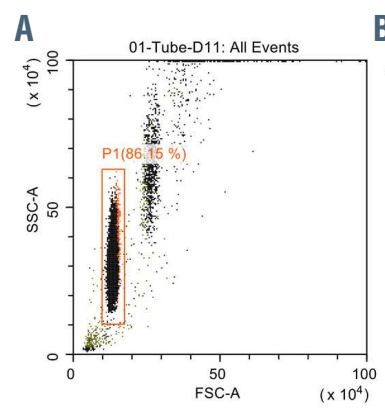

D

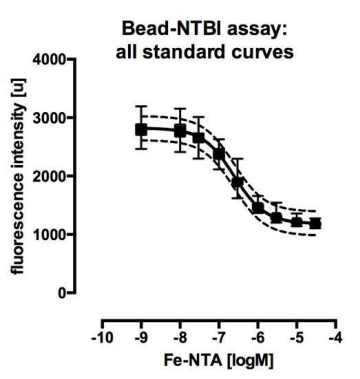

B

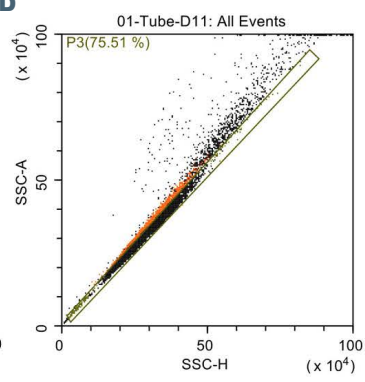

E

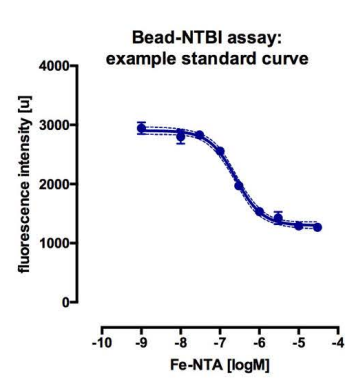

C

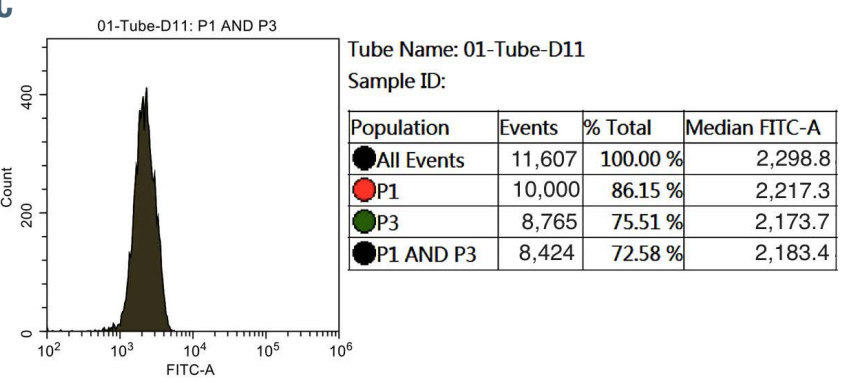

$\mathrm{F}$

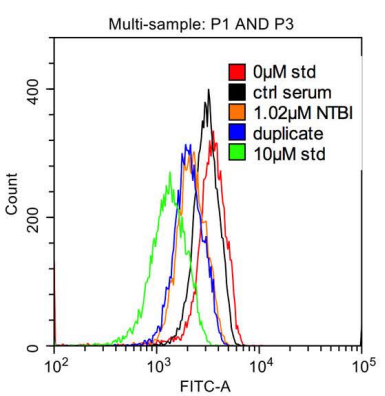

G

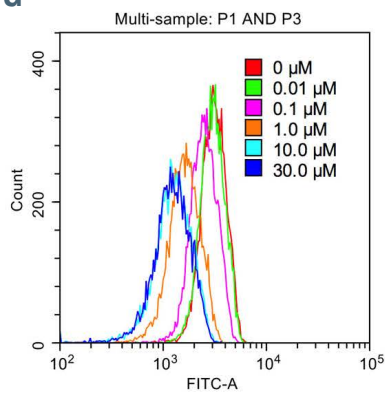

Figure 1. Bead-non-transferrin-bound iron assay. (A) Side-scatter-area versus forward-scatter-area plot, gate P1 identifies a population of CP-851 beads. (B) Sidescatter-area versus side-scatter-height plot, gate P3 excludes doublets: (C) Histogram of FITC-area from combination of P1 and P3 gates, shown with an example statistics (right), median of the distribution represents the bead fluorescence: (D) All 28 standard curves (each in triplicate) plotted together with mean and standard deviation (SD) shown ( $n=84)$, 4-parameter logistic curve fitted $r^{2}=0.97$. (E) Example standard curve with mean and SD shown (triplicates), logM units were transformed by exponentiation and multiplied by $1.0 \times 10^{6}$ to obtain results in $\mu \mathrm{mol} / \mathrm{L}$. (F) Overlay histograms of FITC-area, as in $\mathrm{C}$ above, for buffer ( $0 \mu \mathrm{M}$ ferric nitrilotriacetate [Fe-NTA] standard), control serum, a patient sample in duplicate extrapolated at $1.02 \mu \mathrm{M}$ non-transferrin-bound iron (NTBI) and $10 \mu \mathrm{M}$ Fe-NTA standard, see inset. (G) overlay of FITC-area histograms showing a standard curve example. Limit of Blank ( $95^{\text {th }}$ percentile of eight replicates, LoB) was $0.51 \mathrm{nM}$, Limit of detection

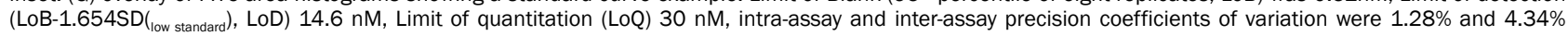
respectively ( 28 consecutively run assays over 82 days, with triplicate controls).

\section{Inductively-coupled plasma mass-spectrometry serum analyses}

A parallel set of serum samples (baseline, 4-312 h) was also analyzed by inductively-coupled plasma mass-spectrometry serum analyses (HPLC-ICPMS) at KCL to measure IVIP-Fe and examine the chromatographic behavior of IVIP. Perkin Elmer Flexar HPLC coupled to a Perkin Elmer NexION 350 D ICPMS was used with Syngistix and Chromera operating software (Figure 2A). Sample preparation, instrumentation, and measurement of IVIP iron in plasma, are detailed in the Online Supplementary Appendix.

\section{Statistical analysis}

All data is presented as mean \pm standard deviation, unless otherwise stated. Analysis of variance (ANOVA) with a post-test Holm-Sidak's multiple comparisons test was used to compare means between treatments. PK parameters were derived from non-compartmental analysis for all subjects using Full Analysis Set ( $c_{\max }$, half-life, and $t_{\max }$ are shown). Area-under-curve (AUC) and nonlinear regression analysis using global fitting was performed on GraphPad Prism (version 6.0). A $P$-value $<0.05$ was considered statistically significant.

\section{Results}

\section{Chromatographic behavior of intravenous \\ iron-carbohydrate complex preparations in serum}

In order to examine the chromatographic behavior of the IVIP in serum, buffered solutions of Fe-carboxymaltose, Fe-sucrose, Fe-isomaltoside-1000 (30 $\mu \mathrm{M})$ were mixed with normal human serum (80/20 vol/vol) and the mixtures were incubated in vitro for $1 \mathrm{~h}$ on the bench top. Samples spiked with the internal standard ferrioxamine
(FO) were then injected into HPLC-ICPMS. IVIP chromatograms in $20 \%$ serum are shown as subtraction plots, with control chromatograms subtracted (Figure $2 \mathrm{~B}$ to D). Ferrotransferrin peak appears at $13.17 \mathrm{~min}$ as a result of rapid iron exchange with apotransferrin (stoichiometric amount of apotransferrin was subtracted) either during the short sample processing at the bench and/or waiting time in the auto-sampler, or directly on the column. The post-subtraction IVIP-Fe recovery was $28 \mu \mathrm{M}$ for Fe-carboxymaltose, $32 \mu \mathrm{M}$ for Fe-isomaltoside-1000, and $23.5 \mu \mathrm{M}$ for Fe-sucrose. Low recovery for Fe-sucrose appears likely due to multiple serial dilutions in ammonium acetate buffer $(\mathrm{pH}=7.4)$ to obtain $30 \mu \mathrm{M}$, with some precipitation or re-speciation (Fe-sucrose $\mathrm{pH}$ 10.5-11.1). The subtraction chromatograms show that Fe-isomaltoside-1000 particularly is distributed very widely (peak at $11 \mathrm{~min}, 126 \mathrm{kDa}$ ), while Fe-carboxymaltose and Fe-sucrose have comparable species distribution peaking at $9.2 \mathrm{~min}(160 \mathrm{kDa})$ and $8.9 \min (165 \mathrm{kDa})$, respectively. Notably, these elution times and therefore $\mathrm{MW}$ ranges do not correspond to the values obtained in the presence of buffers alone..$^{5}$ This difference results most likely from the in vivo formation of the protein corona $^{22}$ and probably aggregation between IVIP cores and plasma proteins.

\section{Patient baseline characteristics}

Patients were balanced between arms for all the baseline parameters (Table 1) with the exception of sex. Screening s-Ferritin ranged between 2.85-27.54 $\mu \mathrm{g} / \mathrm{L}$ (percentiles $\left.25^{\text {th }}, 50^{\text {th }}, 75^{\text {th }}: 8.49,11.05,17.78 \mu \mathrm{g} / \mathrm{L}\right)$, TSAT: $5.11-19.62 \%$ (9.48, 14.00, 17.24\%), and hemoglobin: $12.0-15.4 \mathrm{~g} / \mathrm{dL}$ $(12.5,13.0,13.4 \mathrm{~g} / \mathrm{dL})$. 
Table 1. Baseline parameters.

\begin{tabular}{lccccc}
\hline Blood test & $F C M, n=8$ & $n M, n=8$ & $1 S, n=8$ & Placeloo, $n=4$ & All, $n=28$ \\
Females & 7 & 7 & 7 & 4 & 25 \\
C-Reactive Protein $[\mathrm{mg} / \mathrm{L}]$ & $1.47 \pm 2.18$ & $0.85 \pm 0.84$ & $0.96 \pm 0.65$ & $0.34 \pm 0.16$ & $0.98 \pm 1.29$ \\
\hline Serum Ferritin $[\mu \mathrm{g} / \mathrm{L}]$ & $14.24 \pm 8.8$ & $10.94 \pm 4.77$ & $15.05 \pm 10.39$ & $8.26 \pm 4.33$ & $12.67 \pm 7.89$ \\
Hemoglobin $[\mathrm{g} / \mathrm{L}]$ & $126.5 \pm 5.42$ & $125.5 \pm 9.42$ & $128.37 \pm 11.23$ & $123.25 \pm 4.64$ & $126.28 \pm 8.28$ \\
\hline Hepcidin $[\mathrm{ng} / \mathrm{mL}]$ & $1.07 \pm 1.2$ & $1.36 \pm 2.17$ & $3.27 \pm 2.52$ & $0.67 \pm 0.76$ & $1.72 \pm 2.16$ \\
Iron $[\mu \mathrm{mol} / \mathrm{L}]$ & $10.34 \pm 5.11$ & $13.04 \pm 5.89$ & $9.46 \pm 4.75$ & $12.69 \pm 5.68$ & $11.2 \pm 5.26$ \\
\hline NTBI $[\mu \mathrm{mol} / \mathrm{L}]$ & $0.0 \pm 0.0$ & $0.0 \pm 0.0$ & $0.0 \pm 0.0$ & $0.0 \pm 0.0$ & $0.0 \pm 0.0$ \\
Reticulocytes $\left[10^{9} / \mathrm{L}\right]$ & $61.8 \pm 10.88$ & $56.81 \pm 13.99$ & $53.75 \pm 18.51$ & $60.97 \pm 29.43$ & $57.95 \pm 16.67$ \\
\hline Soluble Transferrin Receptor $[\mathrm{mg} / \mathrm{L}]$ & $1.49 \pm 0.41$ & $1.3 \pm 0.13$ & $1.26 \pm 0.45$ & $1.47 \pm 0.25$ & $1.36 \pm 0.34$ \\
Transferrin $[\mathrm{g} / \mathrm{L}]$ & $3.0 \pm 0.4$ & $2.9 \pm 0.28$ & $2.84 \pm 0.18$ & $3.1 \pm 0.2$ & $2.94 \pm 0.29$ \\
Transferrin Saturation $[\%]$ & $13.81 \pm 7.05$ & $18.07 \pm 8.41$ & $13.55 \pm 7.57$ & $16.65 \pm 8.28$ & $15.36 \pm 7.6$ \\
UIBC $[\mu \mathrm{mol} / \mathrm{L}]$ & $56.68 \pm 9.3$ & $50.95 \pm 8.29$ & $53.97 \pm 8.01$ & $58.35 \pm 10.28$ & $54.51 \pm 8.72$
\end{tabular}

FCM: ferric carboxymaltose; IIM: iron isomaltoside-1000; IS: iron sucrose; NTBI: non-transferrin bound iron; UIBC: unsaturated iron binding capacity.Values given as mean \pm standard deviation.

Table 2. Selected pharmacokinetic parameters of intravenous iron-carbohydrate complex preparations.

\begin{tabular}{|c|c|c|c|c|}
\hline Biomarker & PK parameter & $\begin{array}{l}\text { Ferric carboxymaltose } \\
\qquad n=8\end{array}$ & $\begin{array}{l}\text { Iron isomaltoside } 1,000 \\
n=8\end{array}$ & $\begin{array}{c}\text { Iron sucrose } \\
n=8\end{array}$ \\
\hline IVIP iron content & $\begin{array}{c}\mathrm{c}_{\max }, \text { mean } \pm \mathrm{SD}[\mathrm{mmol} / \mathrm{L}] \\
\mathrm{t}_{\max } \text {, mean }(\min -\max )[\mathrm{h}] \\
\mathrm{t}^{1} / 2, \text { mean } \pm \mathrm{SD}[\mathrm{h}] \\
\mathrm{AUC}_{0 \text {-inf }}\left[\mathrm{h}^{*} \mathrm{mmol} / \mathrm{L}\right]\end{array}$ & $\begin{array}{c}1.16 \pm 0.09 \\
0.34(0.33-0.7) \\
6.82 \pm 1.93 \\
12.39 \pm 1.2\end{array}$ & $\begin{array}{c}1.29 \pm 0.1 \\
0.67(0.33-6) \\
20.3 \pm 2.27 \\
36.76 \pm 4.9\end{array}$ & $\begin{array}{c}0.85 \pm 0.17 \\
0.35(0.33-0.37) \\
3.43 \pm 1.55 \\
2.59 \pm 0.5\end{array}$ \\
\hline Total serum iron & $\begin{array}{c}\mathrm{c}_{\max }, \text { mean } \pm \mathrm{SD}[\mathrm{mmol} / \mathrm{L}] \\
\mathrm{t}_{\max }, \text { mean }(\min -\mathrm{max})[\mathrm{h}] \\
\mathrm{t} 1 / 2, \text { mean } \pm \mathrm{SD}[\mathrm{h}] \\
\mathrm{AUC}_{0 \text {-inf }}\left[\mathrm{h}^{*} \mathrm{mmol} / \mathrm{L}\right]\end{array}$ & $\begin{array}{c}1.18 \pm 0.1 \\
0.33(0.18-0.7) \\
11.14 \pm 3.42 \\
14.8 \pm 1.22\end{array}$ & $\begin{array}{c}1.3 \pm 0.1 \\
0.68(0.33-6) \\
19.21 \pm 2.97 \\
38.5 \pm 4.13\end{array}$ & $\begin{array}{c}0.89 \pm 0.21 \\
0.34(0.18-0.37) \\
7.5 \pm 1.76 \\
4 \pm 0.53\end{array}$ \\
\hline Transferrin-bound iron & $\begin{array}{c}\mathrm{c}_{\max }, \text { mean } \pm \mathrm{SD}[\mu \mathrm{mol} / \mathrm{L}] \\
\mathrm{t}_{\text {max }}, \text { mean }(\min -\max )[\mathrm{h}] \\
\mathrm{tl}^{1} / 2, \text { mean } \pm \mathrm{SD}[\mathrm{h}] \\
\mathrm{AUC}_{0 \text {-inf }}\left[\mathrm{h}^{*} \mathrm{mmol} / \mathrm{L}\right]\end{array}$ & $\begin{array}{c}49.13 \pm 7.19 \\
24(4-24) \\
11.45 \pm 4.88 \\
2.09 \pm 0.42\end{array}$ & $\begin{array}{c}38.34 \pm 10.8 \\
8.05(6-24) \\
15.35 \pm 4.44 \\
1.72 \pm 0.49\end{array}$ & $\begin{array}{c}51.27 \pm 4.68 \\
5(4-24) \\
6.82 \pm 1.38 \\
1.37 \pm 0.28\end{array}$ \\
\hline
\end{tabular}

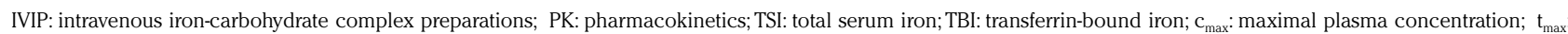
time of maximal plasma concentration; $\mathrm{t} \frac{1}{2}$ : plasma half-life; $\mathrm{AUC}_{0 \text {-inf }}$ : area-under-curve from zero to infinity.

\section{Comparison of intravenous iron-carbohydrate complex iron preparations between treatments}

There were striking differences in biomarker timecourses between IVIP, as shown in Figure 3A to C. For the IVIP-Fe (as TSI-TBI), the elimination rate was slowest, while $c_{\max }$ was highest with Fe-isomaltoside-1000, followed by Fe-carboxymaltose and Fe-sucrose (at median $\mathrm{t}_{\max } 0.67,0.34,0.35 \mathrm{~h}$, respectively), see Table 2 . The $\mathrm{c}_{\max }$ was comparable within $95 \%$ Confidence Interval [CI] for all IVIP (spanning $1 \mathrm{mM}$ value): $1.29 \pm 0.1 \mathrm{mM}$ for Fe-isomaltoside-1000, $1.16 \pm 0.09 \mathrm{mM}$ for Fe-carboxymaltose, and $0.85 \pm 0.17 \mathrm{mM}$ for Fe-sucrose, Figure $4 \mathrm{~A}$, Table 2. The IVIP-Fe AUC differed between treatments $(P<0.0001)$, with Fe-isomaltoside-1000 14-fold higher than Fe-sucrose and 3-fold higher than Fe-carboxymaltose, Fe-carboxymaltose 4.8-fold higher than Fe-sucrose $(P<0.0001$ for all pairs). The between-patient average IVIP-Fe half-life was 10-fold longer for Fe-isomaltoside-1000 $(20.3 \pm 2.27 \mathrm{~h})$ and twice longer for Fe-carboxymaltose $(6.82 \pm 1.93 \mathrm{~h})$ than for Fe-sucrose $(3.43 \pm 1.55 \mathrm{~h})$, Table 2. The chromatographic behavior of IVIP was also monitored using HPLC-ICPMS at KCL (see Methods). Subtraction chromatograms (4hbaseline) show clear differences in IVIP-Fe profiles (Figure 2B), each presenting a distinct chromatographic behavior: Fe-isomaltoside- 1000 has a broad peak eluting at $11.3 \mathrm{~min}$, Fe-carboxymaltose at $9.36 \mathrm{~min}$ and Fe-sucrose at $8.97 \mathrm{~min}$ with a single principal peak each. These ex vivo 100\% serum profiles compare well with the in vitro $20 \%$ serum profiles, Figure 2C (discussed).

\section{Total serum iron changes between treatments}

The time-courses of total serum iron (TSI) closely follow the kinetics of IVIP-Fe, especially for Fe-isomaltoside1000. For Fe-carboxymaltose and Fe-sucrose there is an early separation of IVIP-Fe from the trajectory of TSI (Figure $3 \mathrm{~A}$ to $\mathrm{C}$, green and red profiles, also compare Figure $4 \mathrm{~A}$ and $\mathrm{B})$. This is a consequence of their half-life being much shorter, and thus IVIP-Fe decaying to sufficiently low values for the TBI component now to dominate TSI. TSI $c_{\max }$ is comparable, within $95 \% \mathrm{CI}$, across treatments, and TSI $t_{\max }$ closely corresponds to IVIP-Fe $\mathrm{t}_{\max }$, Figure $4 \mathrm{~B}$, Table 2 . The TSI AUC differed $(P=0.0001)$ between treatments, with Fe-isomaltoside-1000 9.6-fold higher than Fe-sucrose and 2.6-fold higher than Fe-carboxymaltose, while Fe-carboxymaltose 3.7-fold higher than Fe-sucrose $(P<0.0001$ for all pairs).

\section{Transferrin saturation and non-transferrin-bound iron changes between treatments}

TSAT was lower with Fe-isomaltoside-1000 reaching $81.04 \pm 16.52 \%$ at $24 \mathrm{~h}$ (range $60.5-100 \%$ ) versus early full saturation with Fe-sucrose (already at 2 h $95.24 \pm 8.87 \%$, 


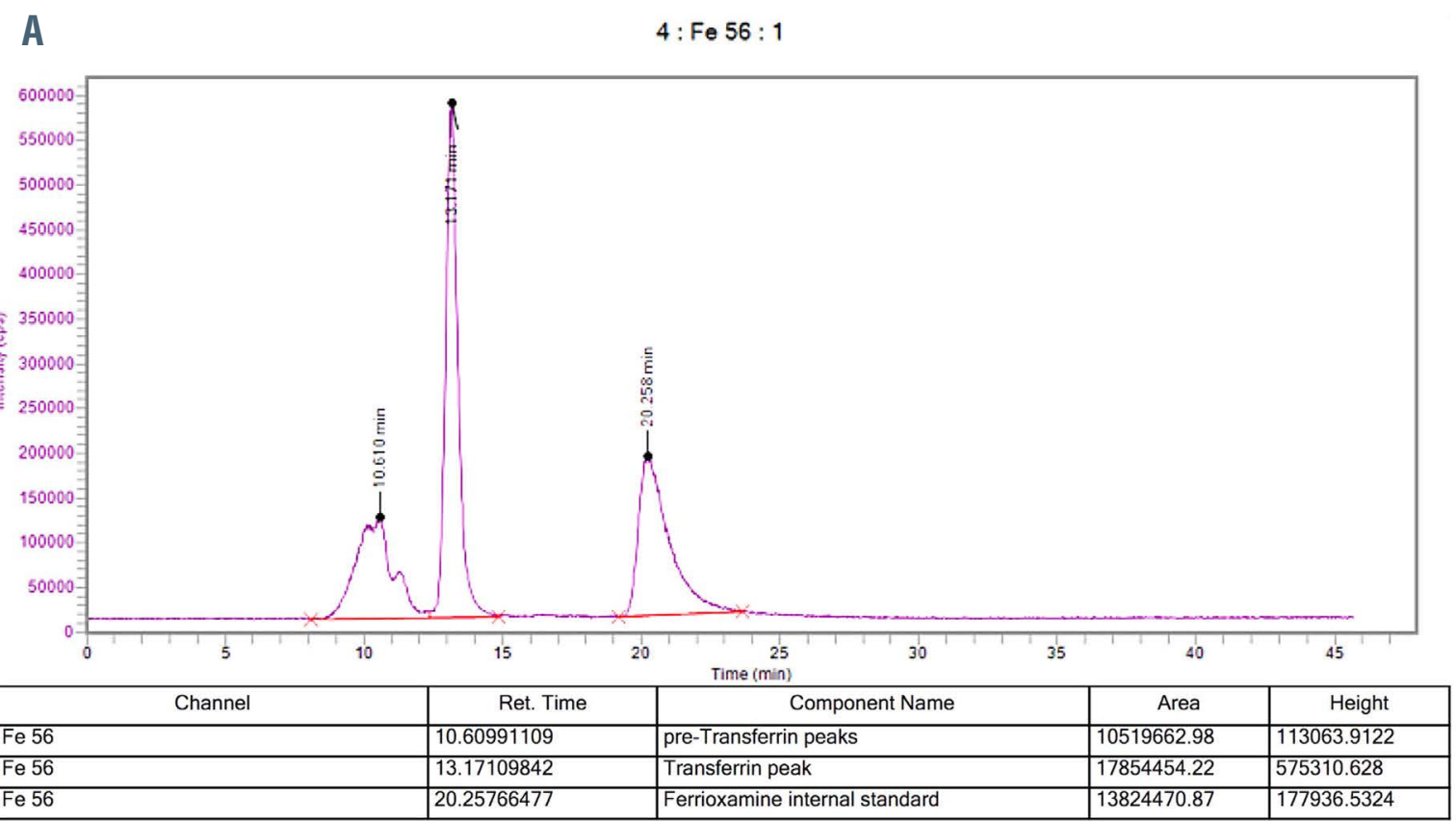

B

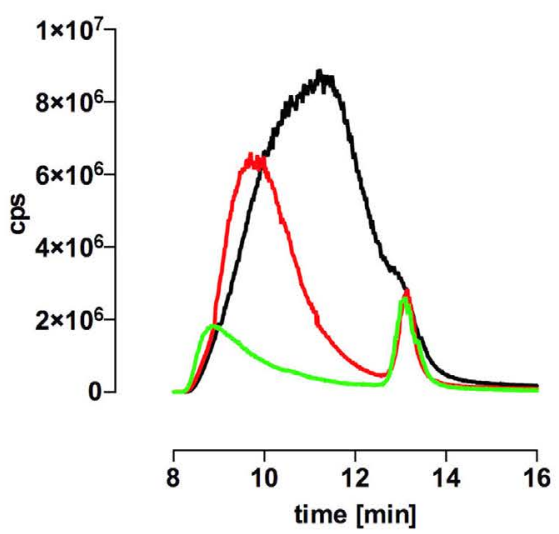

C

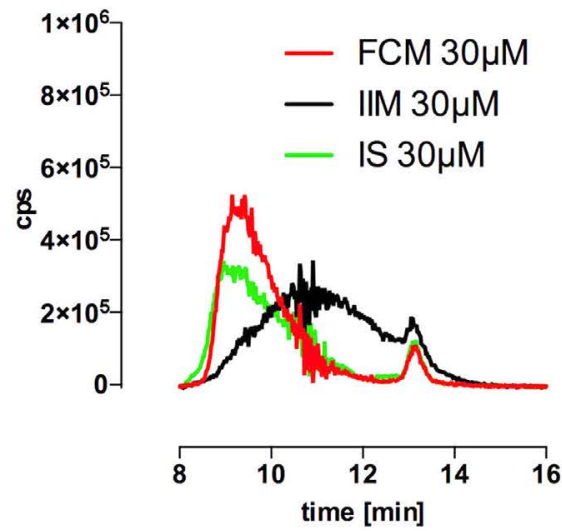

D
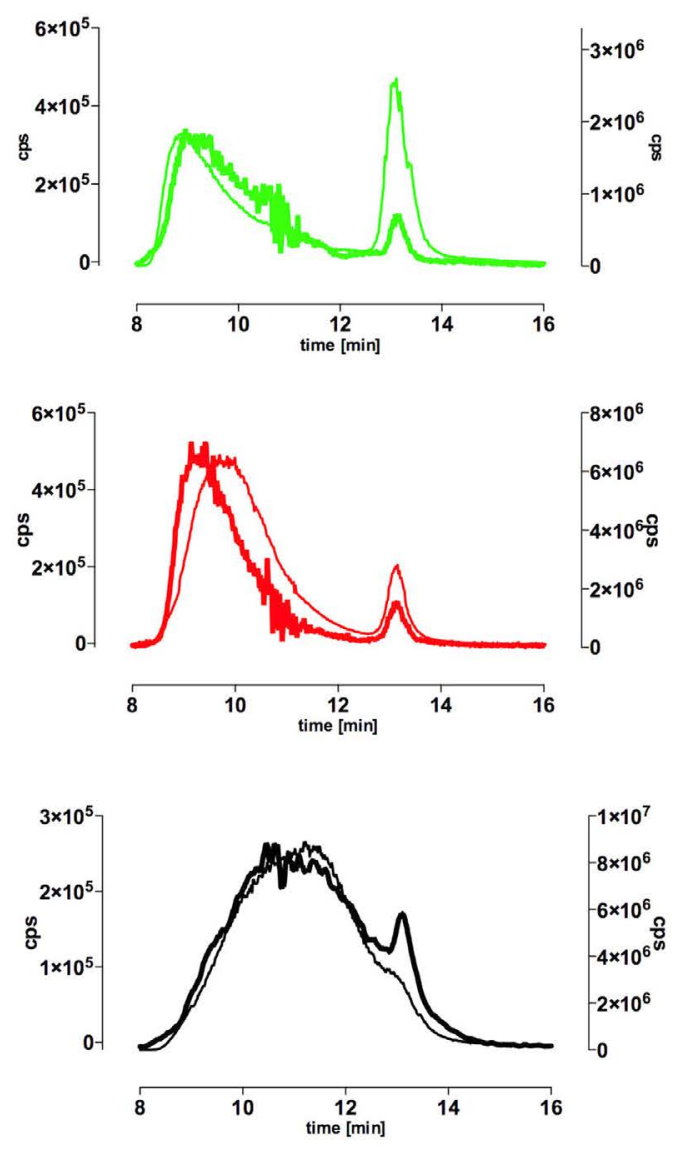

Figure 2. Chromatography of the intravenous iron-carbohydrate complex preparations using HPLC-ICPMS at KCL. (A) An example serum sample high-performance liquid chromatography in combination with inductively coupled plasma mass spectrometry (HPLC-ICP-MS) run with integration of chromatograms within the Chromera software. (B) The subtraction chromatograms of intravenous iron-carbohydrate complex preparations (IVIP) in serum samples (ex vivo), baseline subtracted from the 4 hour (h) time-point. Variable abundance is a function of the given IVIP half-life at $4 \mathrm{~h}$; transferrin peak (at 13.2 minutes [min]) indicates the iron exchange from IVIP to apotransferrin. The precision of subtraction is validated by the overlay of the internal standard (not shown) converging on $15 \mu \mathrm{M}$ FO (subtraction of $5 \mu \mathrm{M}$ from $20 \mu \mathrm{M})$. (C) The subtraction chromatograms of IVIP $(30 \mu \mathrm{M})$ incubated in vitro with $20 \%$ serum for $1 \mathrm{~h}$ with control chromatograms subtracted. Distinct chromatograms for Fe-isomaltoside-1000, Fe-sucrose and Fe-carboxymaltose identified. Small iron signal at 13.2 min is ferrotransferrin testifying to exchange of labile iron between polymers and apotransferrin. (D) Comparison of in vitro (thick) and ex vivo (thin) IVIP chromatograms from B and C using two y-axes for peak size adjustment. At $4 \mathrm{~h}$ post-infusion patient samples show distinct shift of the peak elution time, which indicates that principal IVIP species changes with time i.e., that larger species are preferentially removed from plasma. Fe-carboxymaltose shows greatest shift of peak time. 

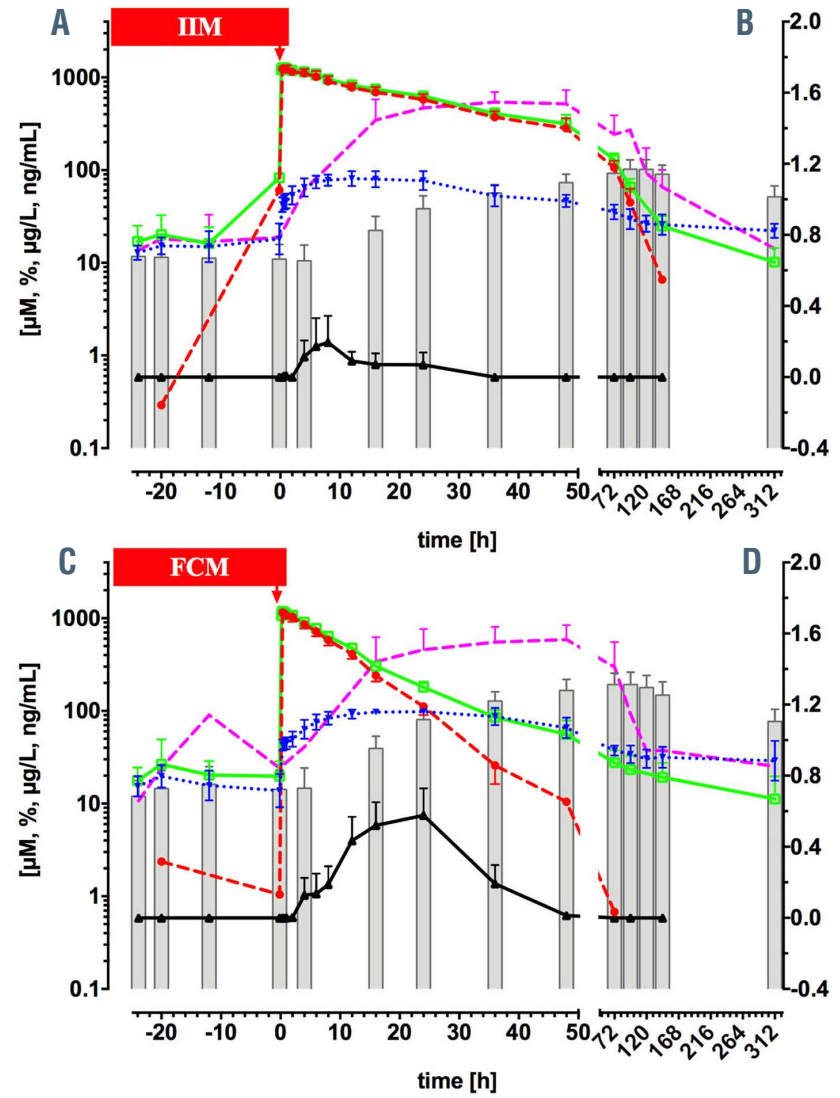

$-\mathrm{NTBI}[\mu \mathrm{M}]$
serum ferritin $[\mu \mathrm{g} / \mathrm{L}]$
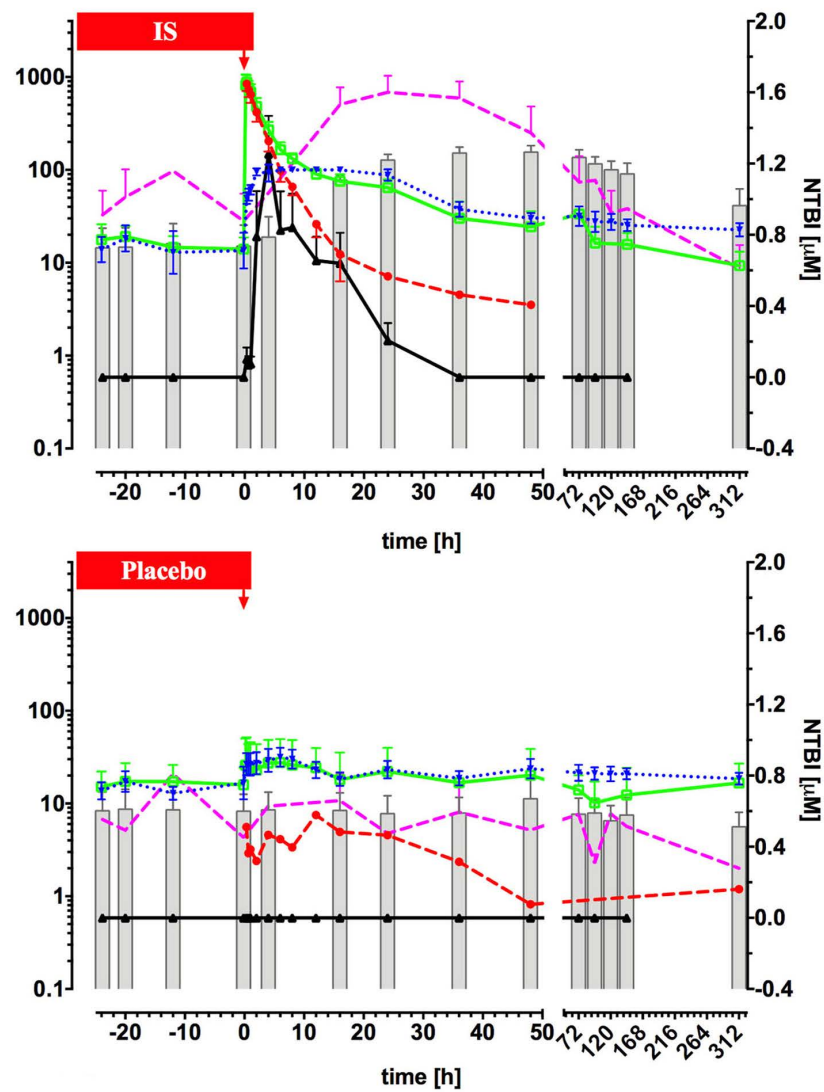

...... TSAT [\%]

-a- IVIP-Fe $[\mu \mathrm{M}]$

- total serum iron $[\mu \mathrm{M}]$

Figure 3. Aggregate profiles of key iron metabolism parameters. Intravenous iron-carbohydrate complex preparation (IVIP) is infused at time 0 hours (h) (red arrow), with time $<0 \mathrm{~h}$ indicating baseline values, see legend for graph explanation: non-transferrin-bound iron (NTBI) (black) is plotted on the right y-axis, all other variables - on the log axis (left $y$-axis); note hepcidin concentration is multiplied by 10 to enable plotting on the log axis. (A) Fe-isomaltoside-1000, $n=8$; (B) Fe-sucrose, $n=8$; (C) Fe-carboxymaltose, $n=8$; (D) placebo, $n=4$.

range 79.2-100\%), and later full saturation with Fe-carboxymaltose at $16 \mathrm{~h}(97.00 \pm 8.49$, range $76-100 \%)$, Figure 4C. TSAT AUC barely differed between treatments; for Fe-carboxymaltose versus Fe-isomaltoside- 1000 by only 32\% $(P=0.048)$ with other comparisons statistically insignificant. NTBI was relatively low with Fe-isomaltoside-1000 (peak $0.13 \pm 0.27 \mu \mathrm{M}$ at $8 \mathrm{~h}$ ), but appeared high notably rapidly with Fe-sucrose $(0.79 \pm 0.72 \mu \mathrm{M}$ at $2 \mathrm{~h}$, peak $1.25 \pm 0.61 \mu \mathrm{M}$ at $4 \mathrm{~h}$ ), and was delayed with Fe-carboxymaltose (peak at $0.58 \pm 0.43 \mu \mathrm{M}$ at $24 \mathrm{~h}$ ), Figure 4D. The first appearance of NTBI associated with relatively low TSAT, likely related to the rate of iron release from the IVIP. The peak NTBI values were associated with full TSAT (or near-saturation in Feisomaltoside-1000 group) and the disappearance of NTBI precedes (occurs before) the normalization of TSAT, compare Figure $4 \mathrm{C}$ and D. In contrast to TSAT AUC, the NTBI AUC differed significantly $(P=0.01)$ between groups on average, with Fe-carboxymaltose nearly 7 -fold higher than Fe-isomaltoside-1000 ( $P=0.04)$, Fe-sucrose versus Fe-isomaltoside-1000 nearly 9-fold higher $(P=0.01)$ while for Fesucrose versus Fe-carboxymaltose only 1.15-fold higher ( $P=$ not significant $)$.

\section{Hepcidin changes between treatments}

Hepcidin peaks earlier with Fe-sucrose to $68.6 \pm 34.7$ $\mathrm{ng} / \mathrm{mL}$ at $24 \mathrm{~h}$, than with Fe-isomaltoside-1000 to $54.3 \pm 15.2 \mathrm{ng} / \mathrm{mL}$ at $36 \mathrm{~h}$ and than with Fe-carboxymaltose to $58.9 \pm 25.2 \mathrm{ng} / \mathrm{mL}$ at $48 \mathrm{~h}$. All hepcidin AUC were similar $(P=0.54)$, Figure 4E. This is in keeping with similar exposure of hepatocytes to TSAT (transferrin-Fe2) between treatments: see above. Furthermore, it indicates the NTBI exposure (AUC) differences do not influence the exposure to hepcidin.

\section{s-Ferritin changes between treatments}

s-Ferritin showed significant differences between treatments, increasing faster with time for both Fe-sucrose and Fe-carboxymaltose and slower for Fe-isomaltoside-1000. Ferritin increase from $\sim 12 \mu \mathrm{g} / \mathrm{L}$ at baseline was greatest for Fe-carboxymaltose to $\sim 200 \mu \mathrm{g} / \mathrm{L}$ at $72 \mathrm{~h}$ with an exponential constant $\mathrm{k}=0.028 \pm 0.013 \mu \mathrm{g} / \mathrm{L}^{*} \mathrm{~h}$, followed by $\mathrm{Fe}$ sucrose to $\sim 150 \mu \mathrm{g} / \mathrm{L}$ at $36 \mathrm{~h} \mathrm{k}=0.076 \pm 0.022 \mu \mathrm{g} / \mathrm{L}^{*} \mathrm{~h}$, and Fe-isomalt side- 1000 to $\sim 102 \mu \mathrm{g} / \mathrm{L}$ at $96 \mathrm{~h}, \mathrm{k}=0.021 \pm 0.014$ $\mu \mathrm{g} / \mathrm{L} * \mathrm{~h}$ (Figure 4F, Figure $5 \mathrm{~A}$ and $\mathrm{C}$ ). Ferritin AUC differed between groups $(P<0.0001)$, Fe-carboxymaltose being $75 \%$ higher $(P=0.007)$ than Fe-isomaltoside-1000 and $63 \%$ higher $(P=0.01)$ than Fe-sucrose, with comparable AUC for Fe-isomaltoside-1000 and Fe-sucrose $(P=0.98)$. All IVIP had greater ferritin AUC versus placebo: 9-, 10-, and 16fold for Fe-isomaltoside-1000, Fe-sucrose and Fe-carboxy- 
A

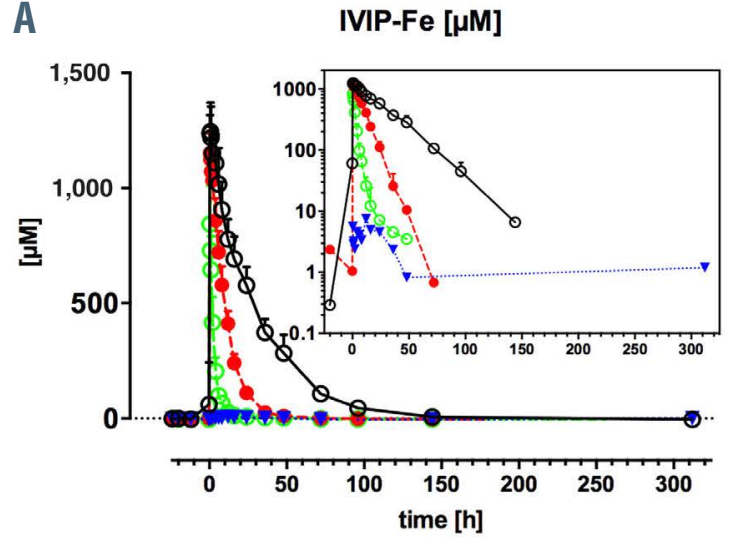

TfSat [\%]

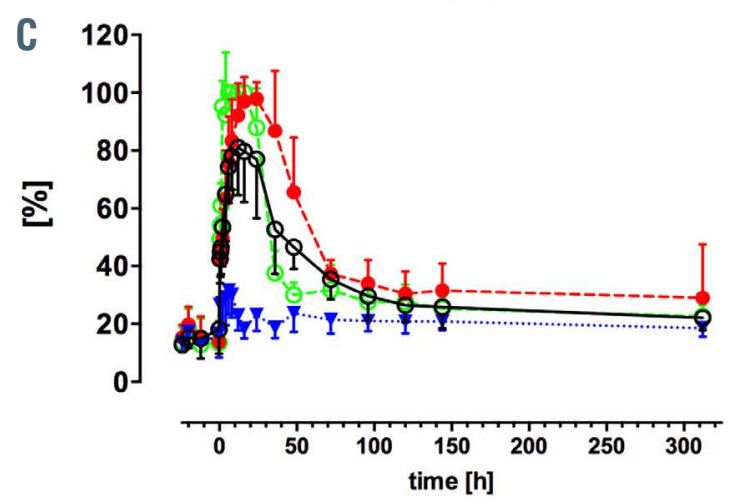

hepcidin $\left[10^{*} \mathrm{ng} / \mathrm{mL}\right]$

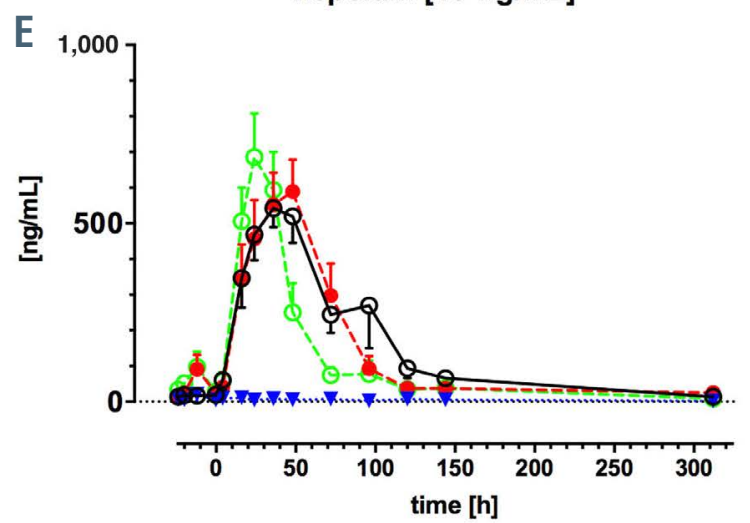

B

total serum iron $[\mu \mathrm{M}]$

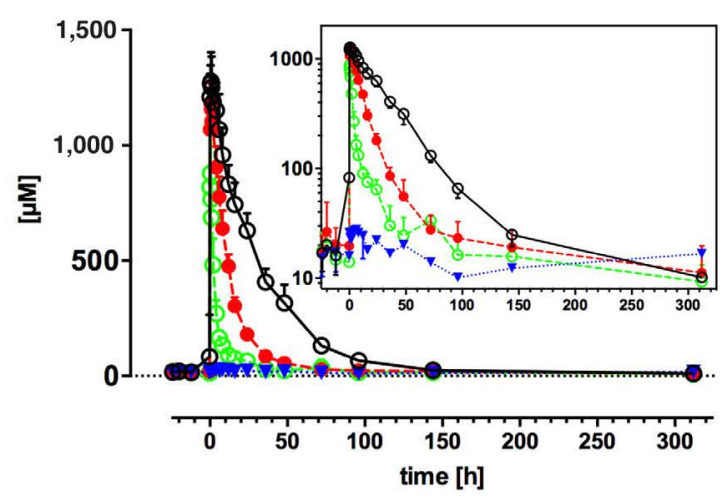

bead-NTBI $[\mu \mathrm{M}]$

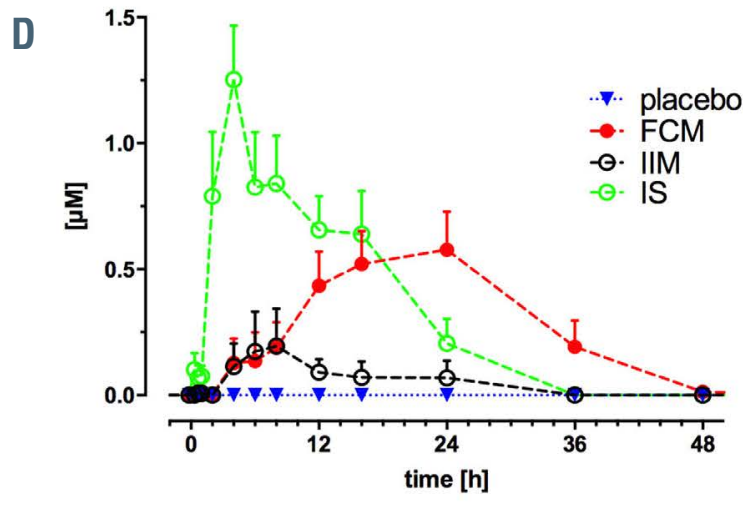

F

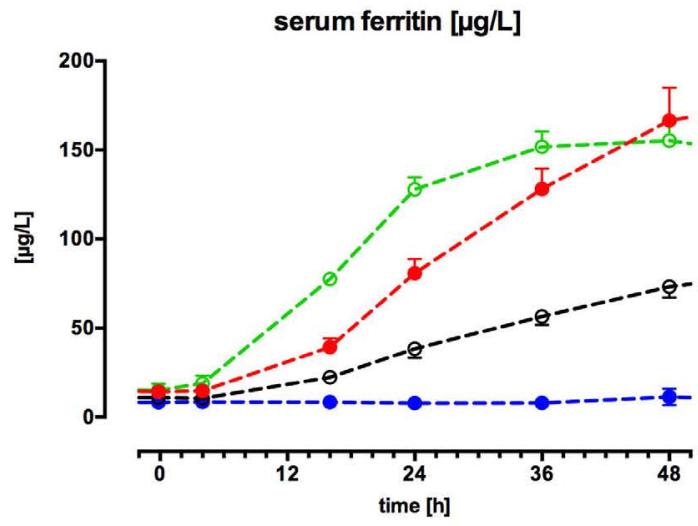

Figure 4. Aggregate data of intravenous iron-carbohydrate complex iron preparations, total serum iron, transferrin saturation, non-transferrin-bound iron, hepcidin and ferritin for all patients. Data shown in aggregate for treatment groups: placebo (blue), Fe-carboxymaltose (red), Fe-isomaltoside-1000 (black), Fe-sucrose (green). (A) intravenous iron-carbohydrate complex iron preparations (IVIP-Fe) plasma concentrations (log scale in the inset), estimated from the pre-transferrin chromatographic peak area-under-curve (AUC); (B) total serum iron (log scale in the inset); (C) transferrin saturation (TSAT); (D) non-transferrin-bound iron (NTBI), x-axis limited to 48 hours $(\mathrm{h})$ as no appearance of NTBI after $48 \mathrm{~h}$ was observed; $(\mathrm{E})$ plasma hepcidin $(10 * \mathrm{ng} / \mathrm{mL})$, i.e., measured hepcidin values are lower by a factor of 10 ; $(\mathrm{F})$ serum ferritin during the initial $48 \mathrm{~h}$ for direct comparison with NTBI in D.

maltose, respectively, Figure 5B. s-Ferritin iron content changes between treatments and the erythropoietic response are presented in the Online Supplementary Appendix.

\section{Discussion}

NTBI typically appears as the primary pathological culprit of parenchymal hemosiderosis ${ }^{23}$ in chronic iron overload conditions: hereditary hemochromatosis, ${ }^{24}$ tha- lassemias, ${ }^{25}$ sickle cell anemia, ${ }^{26}$ rare anemias, ${ }^{27,28}$ myelodysplasia ${ }^{29,30}$ and myeloablation. ${ }^{31,32}$ Different NTBI species and other factors ${ }^{33}$ may determine variable distribution of tissue hemosiderosis. ${ }^{4}$ NTBI levels vary by disease, degree of transfusion dependence, and the assays used to detect them, ${ }^{2,34}$ but can be as high as $8.5 \mu \mathrm{M} .^{35}$ In contrast, NTBI appearance is transient after oral or IV iron administration. In studies of single dose oral iron at doses equivalent to $100 \mathrm{mg}$ of ferrous sulphate, NTBI concentrations measured by various methodologies ranged from 1 to $6 \mu \mathrm{M} .^{36-39}$ In this study, maximal NTBI concentrations 

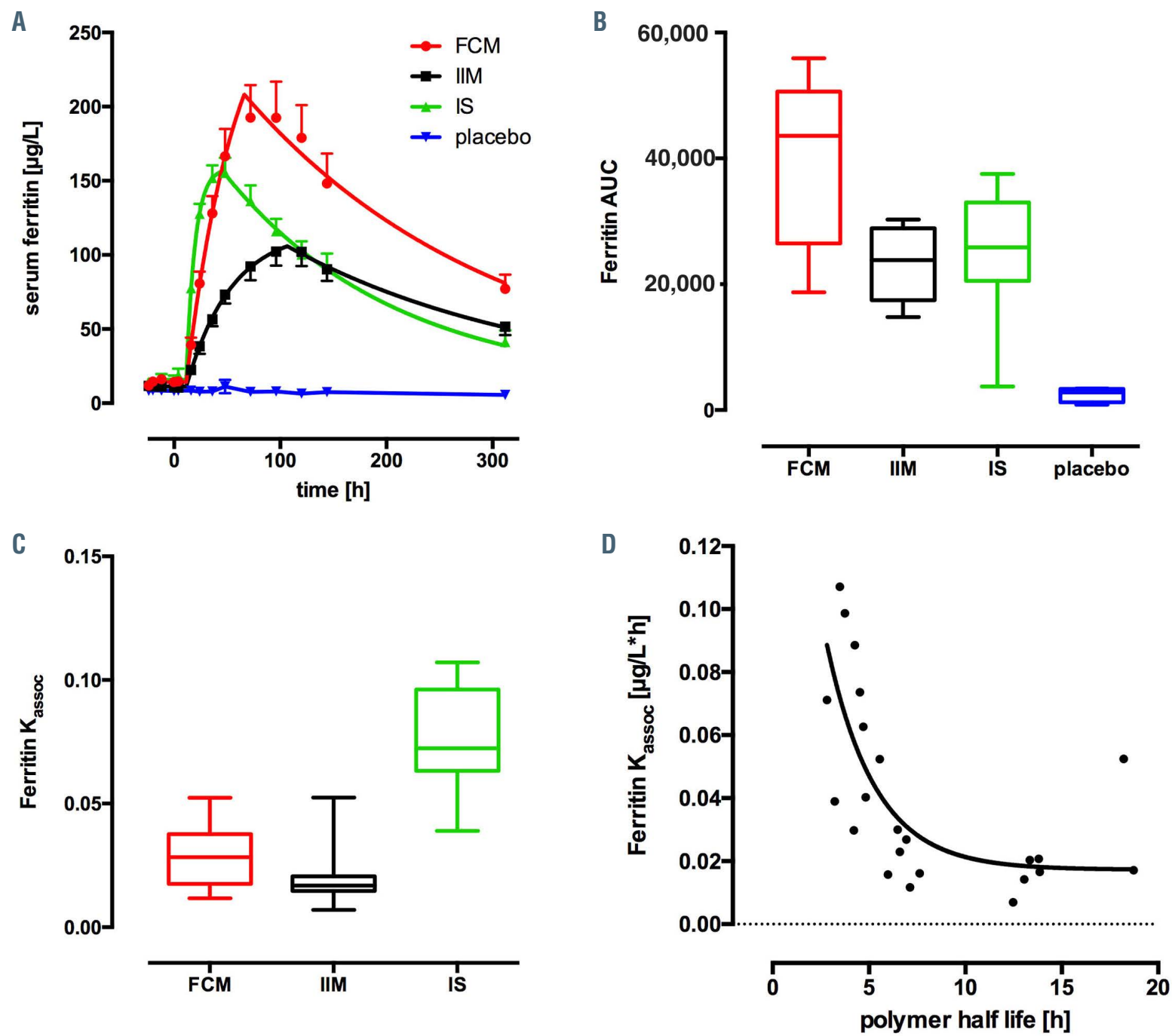

Figure 5. Serum ferritin behavior on study. (A) Cumulative serum ferritin profiles for treatment groups, fitted using global fitting with a custom function (plateau followed by mono-exponential association followed by mono-exponential decay), standard error of the mean, global fit R square 0.84; (B) box-and-whisker plots of ferritin area-under-curve (AUC) (baseline 312 hours); (C) box-and-whisker plots of ferritin mono-exponential association rate constant $\mathrm{K}_{\text {assoc }}$ ( (D) relationships of the rate of increase in serum ferritin to the plasma half-life of the intravenous iron-carbohydrate complex preparations (IVIP).

ranged from 0.13 to $1.25 \mu \mathrm{M}$ (Fe-sucrose $>$ Fe-carboxymaltose $>$ Fe-isomaltoside-1000), being at the lower end of concentrations observed after oral administration. We also measured labile plasma iron ${ }^{40}$ which reflects the activity of redox-active NTBI subspecies, but its levels were lower than measured NTBI concentrations $(0.83,0.15$ and $0.18 \mu \mathrm{M}$ for Fe-sucrose, Fe-isomaltoside-1000 and Fe-carboxymaltose, respectively, data not shown). NTBI appearance associated with oral or IV iron administration has been associated with acute increases in non-specific biomarkers of oxidative stress in clinical studies. ${ }^{41-44}$ However, several epidemiologic studies and a recent prospective clinical trial have not shown that IVIP administration is associated with adverse cardiovascular outcomes. ${ }^{45,46}$ Analyses of large dialysis patient datasets have shown modest associations with increased infections at higher doses, however, this was not observed in the recent prospective clinical trial in chronic kidney disease patients. $^{47,48}$

Although NTBI appearance following oral ${ }^{36-39,49}$ and intravenous iron administration of different formulations is described, ${ }^{17,18,50}$ here we present a unique study directly comparing three IVIP (Fe-isomaltoside-1000, Fe-sucrose, Fe-carboxymaltose). We compared six associated iron metabolism parameters over 2 weeks with complex kinetics unique to each formulation identified for the first time.

We reported increases in IVIP-Fe, TSI, TSAT, s-Ferritin, hepcidin, and NTBI, which returned to baseline within 2 weeks, or sooner, except for s-Ferritin and TSAT (Figure 3 to 5). Based on the corresponding AUC, Fe-isomaltoside1000 resulted in the highest TSI exposure but the lowest TSAT, s-Ferritin, and NTBI. Fe-sucrose resulted in the lowest TSI exposure, intermediate TSAT and s-Ferritin exposure but highest NTBI exposure. Fe-carboxymaltose resulted in intermediate TSI and NTBI exposure, but highest TSAT and s-Ferritin exposure. Increased hepcidin levels were similar for the three IVIP. Thus, the exposure to bioavailable iron, as judged from s-Ferritin and TSAT AUC, was highest for Fe-carboxymaltose, followed jointly by Fesucrose and Fe-isomaltoside-1000. For the latter two preparations, kinetics of iron bioavailability differed in that the short-term bioavailability rate was markedly greater for $\mathrm{Fe}$ sucrose due to its known more limited stability profile (Figure 5A green vs. black curve). ${ }^{6}$ Although head-to-head 


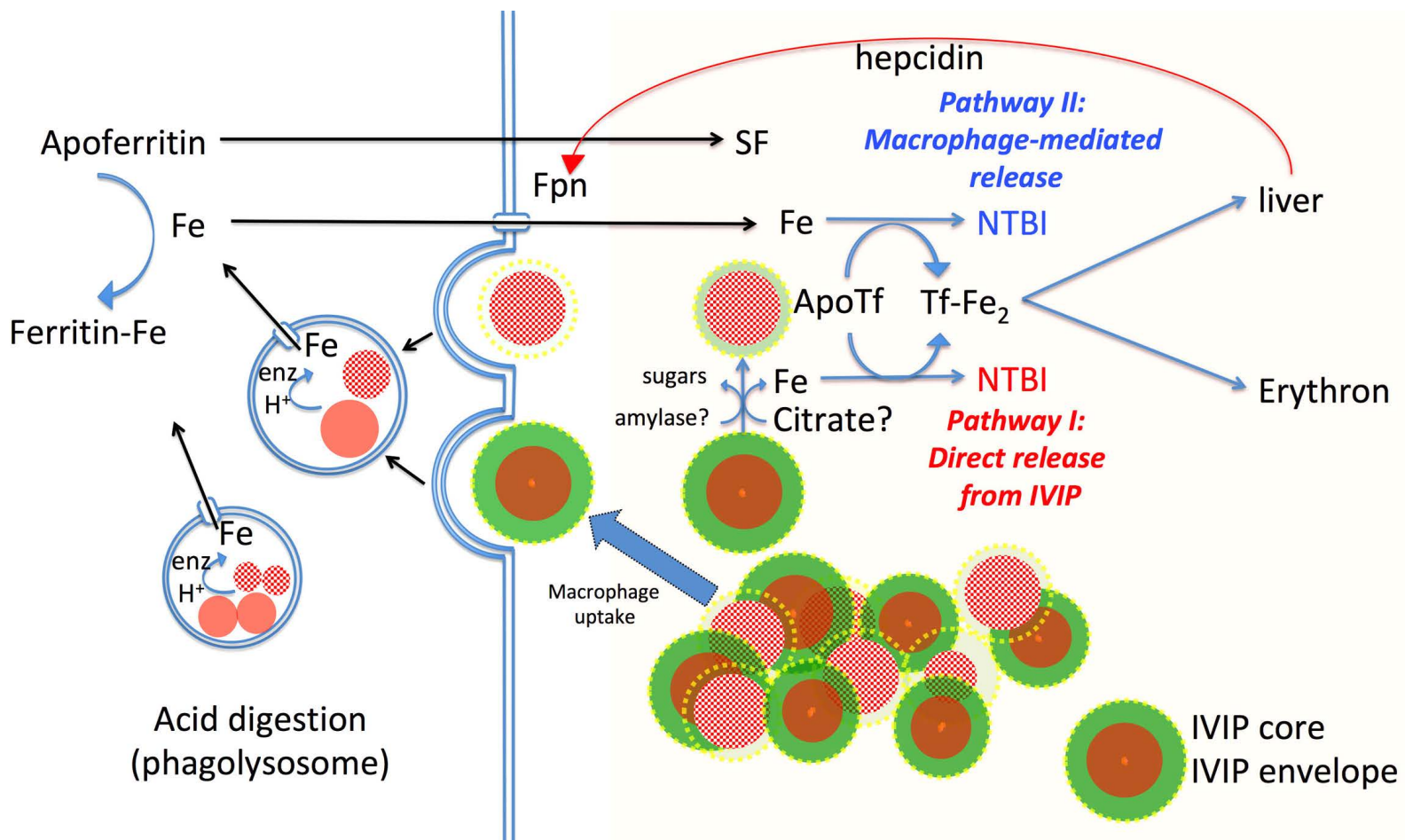

Figure 6. Schematic model of intravenous iron-carbohydrate complex preparations-dependent generation of non-transferrin-bound iron from two compartments. Before intravenous iron-carbohydrate complex preparations (IVIP) are eventually taken up by macrophages, small proportion of circulating IVIP may directly release loosely bound iron as non-transferrin-bound iron (NTBI) or release iron at sufficiently high rate to generate NTBI despite apotransferrin (ApoTf) presence in hypoferremic state (Pathway I: direct release from IVIP). Following macrophage uptake, ferroportin (Fpn)-dependent release of NTBI (Pathway II: Macrophage-mediated release) is the default NTBI route. iron, Tf-Fe ${ }_{2}$ : transferrin-Fe $\mathrm{F}_{2}$; Fpn: ferroportin; SF: serum ferritin.

comparison studies between Fe-carboxymaltose, Fesucrose, and Fe-isomaltoside-1000 looking at clinically meaningful outcomes are lacking, we speculate that relatively higher iron bioavailability for Fe-carboxymaltose could be responsible for the positive effect shown on outcomes in heart failure in comparison with oral iron. ${ }^{51-53}$

This is the first report of IVIP-Fe kinetics measured directly for Fe-isomaltoside-1000, Fe-sucrose and Fe-carboxymaltose rather than indirectly using TSI as a proxy for IVIP-Fe. This matters particularly for Fe-carboxymaltose and Fe-sucrose where the separation between IVIP-Fe and TSI trajectories is particularly apparent (Figure $3 \mathrm{~B}$ and C); thus their $t_{1 / 2}$ is twice longer with the TSI than the IVIP-Fe method (Table 2). This study shows that, for Fecarboxymaltose and Fe-sucrose, the assumption that IVIP$\mathrm{Fe}=\mathrm{TSI}$ is incorrect, especially for lower doses. We also confirmed relative differences in the IVIP half-lives (Fe-isomaltoside-1000 $>$ Fe-carboxymaltose $>$ Fe-sucrose) although the absolute values differed from those published previously, ${ }^{5}$ most likely due to the lower doses used.

Plasma hepcidin increments after IVIP injection have been described. ${ }^{18,54,55}$ Here we show hepcidin peak following the TSAT peak by 20-24 h with all IVIP (Figure 4C and E). This likely reflects the negative feedback between transferrin- $\mathrm{Fe}_{2}$ and hepcidin expression. In hepatocytes TfR1-TfR2-HFE-BMPR interaction positively regulates BMPR signaling to hepcidin transcription. ${ }^{56,57}$ This peakto-peak lag between TSAT and hepcidin is shorter for Fesucrose $(18-22 \mathrm{~h})$. One explanation is that additional positive signaling to hepcidin expression occurs earlier with Fe-sucrose due to higher peak NTBI concentrations. If hepatocyte iron is increased, e.g., rapidly via the NTBI route, this may be sensed by the BMP6 pathway that up- regulates hepcidin expression, and supplements the transferrin-Fe $\mathrm{F}_{2}$-dependent TfR2 signaling.

We relied on three parameters established to address this subject, namely on the differences between IVIP in the peak time and the magnitude of the rise and fall of NTBI levels relative to the peak time, on the magnitude and the rate of the rise and fall of s-Ferritin, as well as including the mutual temporal relationships between them.

We propose two mechanisms for the generation of the kinetic profiles of NTBI, Figure 4D and F. The Fe-sucrosegenerated NTBI profile features two distinct kinetic components: a rapid onset and an early peak at $4 \mathrm{~h}$ followed by decay and a secondary peak/shoulder at $16 \mathrm{~h}$ disappearing at $36 \mathrm{~h}$ (individual profiles are bi- or tri-modal, but the peak times and magnitudes vary across patients possibly due to the effect of protein corona, data not shown). The first peak represents predominantly the rapid release into plasma of weakly-bound iron directly from circulating complexes, because the said $4 \mathrm{~h}$ peak occurs within the first plasma half-life of Fe-sucrose (henceforth Pathway I). This can occur even when transferrin is not fully saturated and is dependent on rate of release of iron from the formulation, the iron-ligand speciation, and the kinetic binding equilibrium of transferrin. ${ }^{38,43,58}$ In contrast, because the second peak/shoulder occurs after four half-lives, at which time over $90 \%$ of Fe-sucrose has been taken up by macrophages, that $16 \mathrm{~h}$ NTBI peak predominantly represents indirect, ferroportin-mediated iron efflux from macrophages that fully saturates transferrin (henceforth Pathway II), Figure 6.

With Fe-isomaltoside-1000, given its long plasma halflife, the small NTBI peak at $8 \mathrm{~h}$ thus represents direct iron 
release from circulating IVIP, while any indirect release after the first half-life is evidently at much slower macrophage-mediated release rate at which transferrin does not become saturated, and consequently NTBI is virtually absent.

Fe-carboxymaltose initially follows the Fe-isomaltoside1000 NTBI profile corresponding to the direct generation of NTBI, but displays a starkly different behavior reflecting the indirect macrophage iron release with a late NTBI peak at $24 \mathrm{~h}$, at which time approximately four plasma half-lives have already elapsed. This difference between Fe-isomaltoside-1000 and Fe-carboxymaltose may partially be accounted for by differences in plasma half-lives, i.e., by the amount of IVIP having been hitherto taken up by macrophages ( $>90 \%$ of Fe-carboxymaltose and $<60 \%$ of Fe-isomaltoside-1000).

As for the macrophage-mediated uptake process, chromatography of the IVIP shows the average size of IVIP decreasing with time. This effect is more marked for Fecarboxymaltose and Fe-sucrose than for Fe-isomaltoside1000 (shift in peak elution time, Figure 2D; Online Supplementary Figure S4). This is best interpreted by macrophages preferentially removing the larger IVIP species and so the smaller species are likely to persist longer in plasma.

The macrophage processing efficiency is higher for Fecarboxymaltose because, according to the s-Ferritin AUC differences (Figure 5B), 75\% more iron per $200 \mathrm{mg}$ dose is extracted from Fe-carboxymaltose than Fe-isomaltoside1000. Plausibly, some unprocessed Fe-isomaltoside-1000 complexes remain in macrophages and are non-bioavailable (at least within 2 weeks, as here). This could be resolved if ferritin were measured sequentially until it reached baseline to enable total s-Ferritin AUC comparison between IVIP. This approach would confirm that the complete s-Ferritin AUC represents the fraction of bioavailable iron at a given dose processed by macrophages, which is not reduced by the fraction that escapes via NTBI route (Pathway I) to parenchymal cells. When NTBI is absent or relatively low as in the case of Feisomaltoside-1000, the difference in complete s-Ferritin AUC between e.g., Fe-carboxymaltose and Fe-isomaltoside- 1000 could mean that a sizeable proportion of the Feisomaltoside-1000 iron remains unprocessed in macrophages. Whether that is due to inherent structural properties of some IVIP or to dysregulation of iron metabolism e.g., high hepcidin in haemodialysis ${ }^{18,59,60}$ or both, remains to be determined. Nevertheless, the relative magnitude of iron shunted away from IVIP via the NTBI plasma compartment to parenchymal cells (hepatocytes) is small (estimated approximately 1,000-times smaller) as compared with the iron flux directed to the erythron from IVIP via the TBI compartment, see the Online Supplementary Figure S6.

The proposed NTBI generation Pathways I and II can be corroborated by comparing NTBI profiles with the rate of s-Ferritin increase (Figure 4D vs. Figure 4F). As s-Ferritin reports macrophage iron content, ${ }^{61,62}$ at 16 hours after Fesucrose injection it is already half-maximal $(\mathrm{s}-$ Ferritin $=\sim 80 \mu \mathrm{g} / \mathrm{L})$, at which time we observe a second NTBI peak/shoulder of $\sim 0.7 \mu \mathrm{M}$ (indicating high rate iron egress exceeding the transferrin iron binding capacity). The fact that for Fe-sucrose at $4 \mathrm{~h}$ the $\sim 1.3 \mu \mathrm{M}$ NTBI peak (and $\sim 0.8 \mu \mathrm{M}$ at $2 \mathrm{~h}$ ) does not correspond to any s-Ferritin increase indicates that the NTBI cannot have arisen from the macrophage compartment, which thus confirms the existence of two separate NTBI generation pathways.

IVIP typically become a source of iron for metabolic pathways after they have been processed by macrophages. ${ }^{16}$ Macrophage uptake rate can be inferred from plasma half-life of IVIP, whereas endolysosomal IVIP degradation rate following macrophage uptake can be inferred from the rate of $s$-Ferritin increase. s-Ferritin increases in plasma as a marker of the iron stored in macrophage cellular ferritin, which undergoes turnover via the transient labile iron pool that regulates ferritin mRNA translation via IRP-IRE system. ${ }^{61}$ Importantly, the faster the IVIP disappears from plasma, the faster s-Ferritin increases (compare IVIP-Fe $t_{1 / 2}$ and the exponential association constant of s-Ferritin increase, Figure 5D), suggesting that the different physicochemical characteristics of the IVIP that influence the half-life ${ }^{6,7}$ are likely to be the fundamental reason for this relationship and hence for the differential iron bioavailability. Thus, Fe-isomaltoside- 1000 is a relatively inert polymer taking longer to be removed by macrophages and longer to release bioavailable iron $(60$ $\mathrm{h}$ longer than Fe-sucrose and $24 \mathrm{~h}$ longer than Fe-carboxymaltose), Figure $5 \mathrm{~A}$.

Significantly, the s-Ferritin decay rate is similar across IVIP (Figure 5A) suggesting a common mechanism of iron egress (macrophage ferroportin), once released from IVIP within endolysosomes. This egress of iron (hence its bioavailability) can be inferred from the fall of macrophage iron stores as reported by falling s-Ferritin.

Similarly, albeit less clearly, IVIP half-life correlates with exposure to NTBI (NTBI AUC), but without associating with either the exposure to TSAT or to hepcidin, Online Supplementary Figure S2A and C. This is consistent with NTBI generation resulting from IVIP rapidly loading the macrophage compartment and iron rapidly egressing (Pathway II) against a hitherto relatively low hepcidin level (thus open ferroportin) where that hepcidin level later increases in response to increased plasma transferrin- $\mathrm{Fe}_{2}$. The rapidity of NTBI appearance with Fe-sucrose versus $\mathrm{Fe}$-carboxymaltose or $\mathrm{Fe}$-isomaltoside- 1000 strongly suggests that ambient iron is immediately made available in plasma for exchange with transferrin until its saturation (Pathway I) before further iron is released via macrophage ferroportin. Rapid NTBI release in vitro from buffered Fe-sucrose was abrogated following $1 \mathrm{~h}$ incubation with normal serum, confirming the released NTBI as apotransferrin-exchangeable (Online Supplementary Figure S5). Thus, Fe-sucrose is more labile than the other IVIP, consistent with our clinical observations, Figure 4D. This in vitro NTBI behavior may result from rapid reconstitution of alkaline Fe-sucrose solution ( $\mathrm{pH}$ 10-11) in plasma ( $\mathrm{pH}$ 7.4) with speciation changes enabling iron donation to the CP851 chelator (or, by extension, an endogenous chelator in vivo e.g., plasma citrate) more rapidly than with Fe-carboxymaltose or Fe-isomaltoside-1000. Furthermore, the protein corona could make a contribution to the stability of the iron core, and macrophage processing of that is unique to each IVIP formulation.

Late onset of NTBI appearance with Fe-carboxymaltose strongly suggests that its iron becomes available to macrophage ferroportin much later, and that the initial rapid release from the formulation directly is negligible (Online Supplementary Figure S5). The crystalline (i.e., more stable) akaganeite-like form of Fe-carboxymaltose iron may be digested differently within endolysosomes than 
the less well defined structure of Fe-sucrose iron. ${ }^{5}$ Although Fe-isomaltoside-1000 and Fe-carboxymaltose both possess akaganeite structures, the core size in Fe-isomaltoside-1000 is smaller. ${ }^{5}$ Thus, differential stability between these two preparations may be explained by different carbohydrate shells or different core sizes of the crystalline iron (hence more significant differences in surface area). ${ }^{6}$

The results of this study should be considered in the context of some limitations. Firstly, the IVIP were all administered at $200 \mathrm{mg}$ doses of elemental iron, which was required to accurately evaluate the complex pharmacokinetic profiles of each formulation. Thus, following the successful model developed in this work, doses that are clinically administered should be studied in the future. It is possible that larger doses may increase NTBI generation by Pathway II or that AUC of s-Ferritin greatly increases if there is a transition from linear to zero-order elimination. Secondly this study did not directly compare different NTBI assays and evaluate their association with the pharmacokinetic and pharmacodynamic profiles of the ironcarbohydrate nano-medicines, however, this is the subject of ongoing work from our group.

In conclusion, IVIP PK and PD support a two-pathway model of NTBI release. Although all IVIP are iron sources, the rate and extent of iron bioavailability differs, following over a 2-week period the sequence $\mathrm{Fe}$ carboxymaltose $>\mathrm{Fe}$-sucrose $>\mathrm{Fe}$-isomaltoside-1000. This strengthens the notion of IVIP as pro-drugs that should not be considered interchangeable. The potential clinical consequences of NTBI on long-term iron bioavailability, efficacy and safety remain unknown and require further studies.

\section{Disclosures}

$M G$ declares consultancy with Vifor Pharma, Imara; $\mathrm{SBa}$ declares no conflict of interest; JP declares honoraria from Celgene, Agios, Protagonist, LaJolla, Silence Therapeutics, bluebird bio, Vifor Pharma, and Cerus, as well as consultancy with Celgene, Agios and Novartis; CM declares employment by Vifor Pharma; SBu declares former employment by Vifor Pharma, RH declares research funding from Renapharma $A B$, and Vifor Pharma.

\section{Contributions}

$M G$ performed the sample analyses, analysed the data and made the figures, designed and wrote the manuscript; SBa performed sample assays; $J P$ co-wrote the manuscript, $C M$ co-wrote the manuscript; SBu designed and oversaw the clinical trial, and co-wrote the manuscript; $R H$ oversaw the sample analysis, codesigned and co-wrote the manuscript. All authors approved the manuscript.

\section{Acknowledgments}

The authors would like to thank Andrew Cakebread who operated the HPLC-ICPMS at KCL and Simon Cheesman who provided the intravenous iron preparations. Vifor Pharma provided blood samples and additional study data. JP would like to acknowledge UCL Biomedical Research Center for Cardiometabolic Program Support.

\section{References}

1. Garbowski MW, Ma Y, Fucharoen S, Srichairatanakool S, Hider R, Porter JB. Clinical and methodological factors affecting non-transferrin-bound iron values using a novel fluorescent bead assay. Transl Res. 2016;177:19-30.e5

2. de Swart L, Hendriks JCM, van der Vorm $\mathrm{LN}$, et al. Second international round robin for the quantification of serum non-transferrin-bound iron and labile plasma iron in patients with iron-overload disorders. Haematologica. 2016;101(1):38-45.

3. Evans RW, Rafique R, Zarea A, et al. Nature of non-transferrin-bound iron: studies on iron citrate complexes and thalassemic sera. J Biol Inorg Chem. 2008;13(1):57-74.

4. Porter JB, Garbowski M. The pathophysiology of transfusional iron overload. Hematol Oncol Clin North Am. 2014; 28(4):683-701.

5. Neiser S, Rentsch D, Dippon U, et al. Physico-chemical properties of the new generation IV iron preparations ferumoxytol, iron isomaltoside 1000 and ferric carboxymaltose. BioMetals. 2015;28(4):615635.

6. Geisser P. Why different iron(III)-oxyhydroxide complexes have different PK/PD characteristics and specific reactivities. J Pharm Nanotechnol. 2016;4(1):14-18.

7. Bhandari S, Pereira DIA, Chappell HF, Drakesmith H. Intravenous irons: from basic science to clinical practice. Pharmaceuticals. 2018;11(3):1-20.

8. Koskenkorva-Frank TS, Weiss G, Koppenol WH, Burckhardt S. The complex interplay of iron metabolism, reactive oxygen species, and reactive nitrogen species: Insights into the potential of various iron therapies to induce oxidative and nitrosative stress. Free Radic Biol Med. 2013;65:1174-1194.

9. Neiser S, Koskenkorva TS, Schwarz K, Wilhelm M, Burckhardt S. Assessment of dextran antigenicity of intravenous iron preparations with enzyme-linked immunosorbent assay (ELISA). Int J Mol Sci. 2016;17(7):1185.

10. Jahn MR, Andreasen HB, Fütterer S, et al. A comparative study of the physicochemical properties of iron isomaltoside 1000 (Monofer $\left.{ }^{\circledR}\right)$, a new intravenous iron preparation and its clinical implications. Eur J Pharm Biopharm. 2011;78(3):480-491.

11. Geisser P, Burckhardt S. The pharmacokinetics and pharmacodynamics of iron preparations. Pharmaceutics. 2011;3(1):1233.

12. Rangel ÉB, Espósito BP, Carneiro FD, et al. Labile plasma iron generation after intravenous iron is time-dependent and transitory in patients undergoing chronic hemodialysis. Ther Apher Dial. 2010; 14(2):186-192.

13. Espósito BP, Breuer W, Slotki I, Cabantchik ZI. Labile iron in parenteral iron formulations and its potential for generating plasma nontransferrin-bound iron in dialysis patients. Eur J Clin Invest. 2002;32(s1):4249.

14. Ma Y, Podinovskaia M, Evans PJ, et al. A novel method for non-transferrin-bound iron quantification by chelatable fluorescent beads based on flow cytometry. Biochem J. 2014;463(3):351-362.

15. Danielson BG. Structure, chemistry, and pharmacokinetics of intravenous iron agents. J Am Soc Nephrol. 2004;15(SUPPL. 2):93-98.

16. Geisser P, Baer M, Schaub E. Structure/his- totoxicity relationship of parenteral iron preparations. Arzneimittelforschung. 1992; 42(12):1439-1452

17. Pai AB, Conner T, McQuade CR, Olp J, Hicks P. Non-transferrin bound iron, cytokine activation and intracellular reactive oxygen species generation in hemodialysis patients receiving intravenous iron dextran or iron sucrose. BioMetals. 2011;24(4):603-613.

18. Kitsati N, Liakos D, Ermeidi E, et al. Rapid elevation of transferrin saturation and serum hepcidin concentration in hemodialysis patients after intravenous iron infusion. Haematologica. 2015;100(3):e80-83.

19. Danielson BG, Salmonson T, Derendorf $H$ Geisser P. Pharmacokinetics of iron(III) hydroxide sucrose complex after a single intravenous dose in healthy volunteers. Arzneimittelforschung. 1996;46(6):615621.

20. Food and Drug Administration (FDA) Draft guidance on iron sucrose. 2012;20122013.

21. Bansal SS, Halket JM, Fusova J, et al. Quantification of hepcidin using matrixassisted laser desorption/ ionization timeof-flight mass spectrometry. Rapid Commun Mass Spectrom. 2009;23(11): 1531-1542.

22. Nguyen VH, Lee B-J. Protein corona: a new approach for nanomedicine design. Int J Nanomedicine. 2017;12:3137-3151.

23. Brissot P, Ropert M, Le Lan C, Loréal O. Non-transferrin bound iron: a key role in iron overload and iron toxicity. Biochim Biophys Acta. 2012;1820(3):403-410.

24. Loreal O, Gosriwatana I, Guyader D, Porter J, Brissot P, Hider RC. Determination of non-transferrin-bound iron in genetic hemochromatosis using a new HPLC- 
based method. J Hepatol. 2000;32(5):727733 .

25. al-Refaie FN, Wickens DG, Wonke B, Kontoghiorghes GJ, Hoffbrand AV. Serum non-transferrin-bound iron in $\beta$-thalassaemia major patients treated with desferrioxamine and L1. Br J Haematol. 1992; 82(2):431-436.

26. Inati A, Musallam KM, Wood JC, SheikhTaha M, Daou L, Taher AT. Absence of cardiac siderosis by MRI T2* despite transfusion burden, hepatic and serum iron overload in Lebanese patients with sickle cell disease. Eur J Haematol. 2009;83(6):565-571.

27. Porter JB, Walter PB, Neumayr LD, et al. Mechanisms of plasma non-transferrin bound iron generation: insights from comparing transfused diamond blackfan anaemia with sickle cell and thalassaemia patients. Br J Haematol. 2014;167(5):692696.

28. Porter JB, Lin KH, Beris P, et al. Response of iron overload to deferasirox in rare transfusion-dependent anaemias: equivalent effects on serum ferritin and labile plasma iron for haemolytic or production anaemias. Eur J Haematol. 2011;87(4):338348.

29. Santini V, Girelli D, Sanna A, et al. Hepcidin levels and their determinants in different types of myelodysplastic syndromes. PLoS One. 2011;6(8):e23109.

30. Cortelezzi a, Cattaneo C, Cristiani S, et al. Non-transferrin-bound iron in myelodysplastic syndromes: a marker of ineffective erythropoiesis? Hematol J. 2000;1(3):153158

31. Bradley SJ, Gosriwitana I, Srichairatanakool S, Hider RC, Porter JB. Non-transferrin-bound iron induced by myeloablative chemotherapy. $\mathrm{Br} \mathrm{J}$ Haematol. 1997;99(2):337-343

32. Sahlstedt L, Ebeling F, von Bonsdorff L, Parkkinen J, Ruutu T. Non-transferrinbound iron during allogeneic stem cell transplantation. Br J Haematol. 2001; 113(3):836-838.

33. Garbowski MW, Evans P, Vlachodimitropoulou E, Hider R, Porter JB. Residual erythropoiesis protects against myocardial hemosiderosis in transfusiondependent thalassemia by lowering labile plasma iron via transient generation of apotransferrin. Haematologica. 2017; 102(10): 1640-1649

34. Garbowski MW, Ma Y, Fucharoen S, Srichairatanakool S, Hider R, Porter JB. Clinical and methodological factors affecting non-transferrin-bound iron values using a novel fluorescent bead assay. Trans Res. 2016:177:19-30.e5

35. Porter JB, Cappellini MD, Kattamis A, et al. Iron overload across the spectrum of nontransfusion-dependent thalassaemias: role of erythropoiesis, splenectomy and transfusions. Br J Haematol. 2016;176(2):288-299.

36. Schmann K, Kroll S, Romero-Abal ME, et al. Impact of oral iron challenges on circulating non-transferrin-bound iron in healthy guatemalan males. Ann Nutr Metab. 2012;60(2):98-107.

37. Schümann K, Solomons NW, Orozco M, Romero-Abal ME, Weiss G. Differences in circulating non-transferrin-bound iron after oral administration of ferrous sulfate, sodium iron EDTA, or iron polymaltose in women with marginal iron stores. Food Nutr Bull. 2013;34(2):185-193.

38. Dresow B, Petersen D, Fischer R, Nielsen P. Non-transferrin-bound iron in plasma following administration of oral iron drugs. Biometals. 2008;21(3):273-276.

39. Hutchinson C, Al-Ashgar W, Liu DY, Hider RC, Powell JJ, Geissler CA. Oral ferrous sulphate leads to a marked increase in pro-oxidant nontransferrin-bound iron. Eur J Clin Invest. 2004;34(11):782-784.

40. Esposito BP, Breuer W, Sirankapracha P, Pootrakul P, Hershko C, Cabantchik ZI Labile plasma iron in iron overload: Redox activity and susceptibility to chelation. Blood. 2003;102(7):2670-2677

41. Erichsen K, Ulvik RJ, Grimstad T, Berstad A, Berge RK, Hausken T. Effects of ferrous sulphate and non-ionic iron-polymaltose complex on markers of oxidative tissue damage in patients with inflammatory bowel disease. Aliment Pharmacol Ther. 2005;22(9):831-838.

42. Khalid S, Shaikh F, Moeen S. Decreased activity of glutathione peroxidase with oral ferrous iron administration: a cause of oxidative stress. Pak J Pharm Sci. 2018; 31(2):405-409.

43. Pai AB, Boyd AV, McQuade CR, Harford A, Norenberg IP, Zager PG. Comparison of oxidative stress markers after intravenous administration of iron dextran, sodium ferric gluconate, and iron sucrose in patients undergoing hemodialysis. Pharmacotherapy. 2007; 27(3):343-350.

44. Kuo KL, Hung SC, Lee TS, Tarng DC. Iron sucrose accelerates early atherogenesis by increasing superoxide production and upregulating adhesion molecules in CKD. J Am Soc Nephrol. 2014;25(11):2596-2606.

45. Kshirsagar AV, Freburger JK, Ellis AR, Wang L, Winkelmayer WC, Brookhart MA. Intravenous iron supplementation practices and short-term risk of cardiovascular events in hemodialysis patients. PLoS One. 2013;8(11):e78930

46. Macdougall IC, White C, Anker SD, et al. Intravenous iron in patients undergoing maintenance hemodialysis. $N$ Engl J Med. 2019;380(5):447-458.

47. Brookhart MA, Freburger JK, Ellis AR, Wang L, Winkelmayer WC, Kshirsagar AV. Infection risk with bolus versus maintenance iron supplementation in hemodialysis patients. J Am Soc Nephrol. 2013; 24(7):1151-1158

48. Macdougall IC, Bhandari S, White C, et al. Intravenous iron dosing and infection risk in patients on hemodialysis: a prespecified secondary analysis of the PIVOTAL trial. J Am Soc Nephrol. 2020;31(5):1118-1127. 49. Schümann K, Solomons NW, Romero-Abal
ME, Orozco M, Weiss G, Marx J. Oral administration of ferrous sulfate, but not of iron polymaltose or sodium iron ethylenediaminetetraacetic acid (NaFeEDTA), results in a substantial increase of nontransferrin-bound iron in healthy iron-adequate men. Food Nutr Bull. 2012;33(2):128136.

50. Scheiber-Mojdehkar B. Non-transferrinbound iron in the serum of hemodialysis patients who receive ferric saccharate: no correlation to peroxide generation. J Am Soc Nephrol. 2004;15(6):1648-1655

51. Van Veldhuisen DJ, Ponikowski P, Van Der Meer P, et al. Effect of ferric carboxymaltose on exercise capacity in patients with chronic heart failure and iron deficiency. circulation. 2017;136(15):1374-1383.

52. Lewis GD, Malhotra R, Hernandez AF, et al. Effect of oral iron repletion on exercise capacity in patients with heart failure with reduced ejection fraction and iron deficiency the IRONOUT HF randomized clinical trial. JAMA. 2017;317(19):1958-1966.

53. Ambrosy AP, Lewis GD, Malhotra $R$, et al. Identifying responders to oral iron supplementation in heart failure with a reduced ejection fraction: a post-hoc analysis of the IRONOUT-HF trial. J Cardiovasc Med. 2019;20(4):223-225.

54. Gaillard CA, Bock AH, Carrera F, et al Hepcidin response to iron therapy in patients with non-dialysis dependent CKD an analysis of the FIND-CKD trial. PLoS One. 2016;11(6):e0157063.

55.Zehra A, Saleh Abdullah SM, Saboor M, Moinuddin. Effect of Intravenous iron supplementation on hepcidin levels in iron deficient pregnant females in second and third trimester. Indian I Hematol Blood Transfus. 2017;33(3):396-401

56. Lin L, Valore E V, Nemeth E, Goodnough JB, Gabayan V, Ganz T. Iron transferrin regulates hepcidin synthesis in primary hepatocyte culture through hemojuvelin and BMP2/4. Blood. 2007;110(6):2182-2189.

57. Ganz T. Hepcidin and iron regulation, 10 years later. Blood. 2011;117(17):4425-4433.

58. Lee $\mathrm{DH}$, Ding $\mathrm{YL}$, Jacobs $\mathrm{DR}$, et al. Common presence of non-transferrinbound iron among patients with type 2 diabetes. Diabetes Care. 2006;29(5):10901095

59. Wish JB. Assessing iron status: beyond serum ferritin and transferrin saturation. Clin J Am Soc Nephrol. 2006;1(Suppl 1):S4S8

60. Wish JB, Aronoff GR, Bacon BR, et al Positive iron balance in chronic kidney disease: how much is too much and how to tell? Am J Nephrol. 2018;47(2):72-83.

61. Rouault TA, Stout CD, Kaptain S, Harford JB, Klausner RD. Structural relationship between an iron-regulated RNA-binding protein (IRE-BP) and aconitase: Functional implications. Cell. 1991;64(5):881-883.

62. Torti FM, Torti SV. Regulation of ferritin genes and protein. Blood. 2002; 99(10): 3505-3516. 